\title{
ESCRITAS DE SI NA WEB: QUESTÕES PARA O SUPORTE DIGITAL
}

\section{ROBSON FONSECA SIMÕES}

Universidade Federal de Rondônia

RESUMO Este artigo, um mergulho na minha tese de doutoramento, tem a vocação de poder problematizar as escritas autobiográficas postadas nas redes sociais escolares do Orkut, trazendo à baila a questão do tempo de duração das narrativas nos suportes digitais. Naquele espaço da web, os navegadores, tripulantes de uma produção histórica do tempo presente, postam as suas histórias escolares do mesmo modo que outras fontes historiográficas apresentam vivas as vozes que clamam por visibilidade nos territórios da História da Educação. Será que os suportes modernos são criados mais para a difusão do que para a conservação, endossando a questão da efemeridade das escritas do universo virtual? Será que os ex-alunos escritores estão conscientes disso? Poder avaliar a documentação, descartar o desnecessário, criar condições de sobrevivência para esses documentos, pode ser um caminho para se poder pensar essa temática. Valho-me dos estudiosos Eco (2010), Mignot (2006), Castillo Gómez (2005), Vidal (2000), e Meneses (2009) para nos ajudar a refletir que as novas tecnologias digitais também têm a sua importância no quesito espaço e guarda de documentos, mesmo com os seus estatutos contraditórios e ambíguos.

Palavras-chave: Redes Sociais do Orkut. Memórias escolares. História da Educação.

\section{ABSTRACT WRITTEN FOR YOU ON THE WEB: ISSUES FOR DIGITAL MEDIA}

This article, a dip in my doctoral thesis, has the vocation to be able to discuss the autobiographical writings posted on social educational networks Orkut, bringing up the question of the length of narrative in digital media. At web space, navigators, crew members of a historical production of this time, post their school stories the same way as other historiographical sources present alive the voices calling for visibility in the territories of History of Education. Is the modern media created more for the diffusion than for conservation, endorsing the issue of the ephemeris of the writings of the virtual universe? 
Are the writers former students aware of it? To assess the documentation, discard the unnecessary, and to create living conditions for these documents can be a way to be able to think about this subject. I turn to Eco (2010), Mignot (2006), Castillo Gómez (2005), Vidal (2000), and Meneses (2009) to help us reflect that new digital technologies also have their importance in the issue space and storage of documents, even with its contradictory and ambiguous statutes.

Keywords: Social Networks of Orkut. School memories. History of Education.

\section{RESUMEN ESCRITO PARA USTED EN LA WEB: TEMAS PARA MEDIOS DIGITALES}

En este artículo, un buceo en mi tesis doctoral, tiene la vocación de problematizar los escritos autobiográficos publicados en redes sociales escolares de Orkut, trayendo a la discusión la cuestión de la duración de la narrativa en medios digitales. En el espacio web, los navegadores, los miembros de la tripulación de una producción histórica de este tiempo, publican sus historias escolares del mismo modo que otras fuentes historiográficas presentan vivas las vozes que claman por visibilidade en los territórios de la História da Educaçión. Será que los soportes modernos son creados más para la difusión que para la conservaçión, endossando la cuestión de la efemeridad de las escritas del universo virtual? Será que los ex-alumnos escritores están concientes de eso? Poder evaluar la documentación, descartar lo innecesariio, crear condiçiones de supervivencia para esos documentos, puede ser un camino para poder pensar esa temática. Me valgo de los estudiosos Eco (2010), Mignot (2006), Castillo Gómez (2005), Vidal (2000) y Meneses (2009) para ayudarnos a reflexionar que las nuevas tecnologías digitales tambiém tienen su importancia en la guarda de documentos, aún con sus estatutos contradictorios y ambiguos.

Palabras clave: Las redes sociales Orkut. Recuerdos de la escuela. Historia de la Educación.

Se vc estudou no internato São Bento do Alto da Boa Vista no Rio de Janeiro de 1964 a 1970, por favor, entre em contato para que possamos relembrar dos velhos tempos! ${ }^{1}$

1 Escrita retirada do Fórum Alunos do Internato da comunidade do Colégio de São Bento do Rio de Janeiro; postada pelo usuário Maurício, em 14/08/2005.
Quem se lembra do Frei Cássio de 65 a 71? Quem lembra da Radio Baiuca? Quem comeu frita no bar do Zé? Quem jogou futebol de tampinha? ${ }^{2}$

2 Escrita retirada do Fórum Que ano? da comunidade do Colégio de São Bento do Rio de Janeiro; postada pelo usuário João R., em 28/08/2005. 
Memórias escolares nas redes sociais virtuais: considerações iniciais

As epígrafes deste texto nos remetem às escritas memorialísticas dos usuários nas comunidades escolares das redes sociais virtuais, mais especificamente do Orkut, o que pode abrir portas para refletirmos sobre o universo da web e os seus diálogos com a História da Educação. No esforço em se poder ampliar esse debate, nos territórios das Ciências Humanas, é possivel também entender que o tempo das tecnologias digitais revolucionou os olhares e as atenções dos sujeitos na história da leitura/escrita; assim, faz-se necessária uma discussão que também leve em conta as lacunas existentes nos suportes digitais.

Quando se adentra e se defronta com os depoimentos saudosistas, nostálgicos, dos usuários nas comunidades escolares da internet, as novas redes sociais virtuais, percebese, nos textos escritos, um tom melancólico dos tempos vividos, as experiências inesqueciveis narradas pelos ex-alunos e as várias histórias contadas do tempo da escola. O conjunto dessas escritas digitais pode oferecer pistas do período passado e permite-nos encontrar descrições variadas sobre a vida cotidiana escolar, as representações de uma época, que podem ser vistas no sentido de Bloch (2001, p. 48) quando afirma: “[...] a diversidade dos testemunhos históricos é quase infinita. Tudo o que o homem diz ou escreve, tudo o que fabrica, tudo o que toca, pode e deve informarnos sobre ele". Assim, talvez possa oferecer inspiração para se procurar entender os possíveis sentidos apreendidos com essas escritas na web, e os que ainda não foram revelados através dos relatos, memórias, histórias, enfim, palavras registradas pelos sujeitos, direcionando, portanto, os holofotes para iluminar novas problemáticas nas escritas de si.
O tempo das tecnologias digitais revolucionou os olhares e as atenções dos sujeitos na história da escrita/leitura; assim, é possivel também entender que novas emoções se tornaram presentes junto à tela do computador, ressignificando as funções e as relações do usuário com os textos na internet; impulsionando-o a postar as suas histórias escolares, pois, relatando nessa rede social, possivelmente, o sujeito pode reduzir a sua solidão na interatividade dos cliques virtuais. Nessa acepção, se quiser, o navegador poderá se lançar à navegação de longo curso entre arquipélagos textuais sem margens nem limites (CHARTIER, 2003) e concentrar a sua sensibilidade na próxima jornada virtual.

Ao investirmos nas escritas digitais com olhares investigativos, tentaremos contemplar os mais diversos caminhos de pesquisas, sobretudo no âmbito das Ciências Humanas, em particular, as da informação, da comunicação e da linguagem. A História da Educação também entra em cena nessa discussão, propondo tornar mais visíveis os caminhos da construção da memória ou das memórias que nos constituem como sujeitos históricos. Nessa acepção, Tfouni (1995) destaca a lenda de Gilgamesh, um dos mais antigos documentos escritos. Diz-se que Gilgamesh, o rei de Uruk, só conseguiu apaziguar sua busca incessante pela imortalidade quando gravou numa pedra toda a sua história, ou seja, quando escreveu os mistérios que viu e as coisas secretas conhecidas. Portanto, é possivel interpretar a lenda de Gilgamesh como uma metáfora: a escrita simbolizando a imortalidade, porque garante a permanência no tempo daquele que escreve.

Mas quem são os guardiões das memórias dos sujeitos? Recorro a Thomson (1997) para tentar responder a essa questão, porque este historiador ratifica a necessidade de ficar atento às várias naturezas de memórias, que 
se acumulam ao longo do tempo, e à pluralidade de versões sobre o passado, fornecidas por diferentes locutores/suportes: fábulas, lendas, músicas, artefatos, escritas, imprensa, mídia, enfim, é possivel pensar em tipologias diversas que mantêm vivas as histórias e os significados históricos, oferecendo, portanto, repertórios variados de fontes aos investigadores para o estudo dessas memórias, de geração em geração.

Pesquisadores brasileiros e estrangeiros vêm se debruçando sobre esses discursos digitais, a partir de várias leituras, investigando o seu caráter criativo, contraditório, pluridimensional, múltiplo e singular. Uma ampliação, em termos históricos, dos trabalhos com a memória é proposta por Lejeune (2008), ao considerar que, atualmente, graças à tecnologia, as escritas e testemunhos de si se apresentam em novas formas na internet. É possivel observar, assim, que as escrituras do eu nos diários, correspondências e blogs, vêm se destacando como fontes de investigação. Este gênero possibilita um ângulo privilegiado para a percepção dos microfundamentos sociais presentes nas escritas de si. Talvez, a reflexão de Lispector (1980, p. 86) - “[...] cada palavra é uma idéia. Cada palavra materializa o espírito. Quanto mais palavras eu conheço, mais sou capaz de pensar o meu sentimento" - possa instigar a produzir os sentidos das escritas digitais dos ex-alunos das comunidades escolares do Orkut.

A memória escrita nessa rede social permite buscar traços de como foram representadas as vivências dos momentos da vida cotidiana escolar. Alguns costumes escolares estão distantes dos regulamentos oficiais das instituições de ensino; nesse sentido, as escritas memorialísticas da comunidade do Orkut cumprem o seu papel, abrindo uma via de acesso ao terreno das memórias autobiográficas, desvelando histórias escolares encenadas no passado e presentificadas nessa rede social virtual.

Rego (2003, p. 204) comenta sobre a narrativa de vida: "ela se reconstrói a cada uma de suas enunciações e reconstrói com ela o sentido da história que enuncia". Com poesia, Britto anuncia em versos, a sua escrita autobiográfica: “Devia ter amado mais, ter chorado mais, ter visto o sol nascer, devia ter arriscado mais [...] ter feito o que eu queria fazer [...] cada um sabe a alegria e a dor que traz no coração.[...]". ${ }^{3}$ Por sua vez, ao analisar a escrita memorialística, Lacerda nos instiga a pensar:

essa escrita pode assumir outras denominações, como romances pessoais, diários intimistas, crônicas memoriais e romances autobiográficos, embora todas elas sejam sobreposições da trilogia clássica ou mais conhecidas: diário - memória - autobiografia. o que diferencia basicamente essas formas literárias de outras são as marcas da escritura do eu e os modos de inscrição de si mesmo, que resultam num pacto denominado por Philippe Lejeune de pacto autobiográfico. (LACERDA, 2003, p. 38)

O mundo das novas tecnologias otimizou novos espaços de comunicação, de sociabilidade, de informação (LÉVY, 1999), o que determinou também, consequentemente, a criação de novos espaços com as memórias dos diaristas. Nos diários on-line, as pessoas também escrevem as suas experiências da vida cotidiana, reclamações, poemas, pensamentos, e, muitas vezes, permitem que outros usuários possam também contribuir com reflexões.

Para alimentar o debate sobre essas questões das escritas autorreferenciais na internet, Lejeune (2008) investigou sobre a prática de escrita do eu na tela do computador. Assim, trazer para o debate o universo das escritas digitais dos usuários, nas comunidades do Orkut, constituiu-se uma possibilidade. Por que os usuários escrevem nessas redes sociais

3 BRITTO, Sérgio. Epitáfio. Disponivel em: <http:www. musica.uol.com.br>. Acesso em: 14 out. 2010. 
virtuais? É possivel pensar que, em frente à tela do computador, os usuários encurtam distâncias de um tempo escolar; diminuindo as saudades, as lembranças escolares se multiplicam, anunciando uma nova prática de escrita, insinuando-se por novos "refúgios do eu" (MIGNOT; CUNHA; BASTOS, 2000)

Chartier (2003, p. 126) destaca: “Com o texto eletrônico, enfim, parece estar ao alcance de nossos olhos e de nossas mãos um sonho muito antigo da humanidade, que se poderia resumir em duas palavras: universalidade e interatividade". Nesse sentido, pode-se supor uma nova caracterização do autor diante do advento do hipertexto eletrônico:

A leitura é sempre apropriação, invenção, produção de significados [...] o leitor é um caçador que percorre terras alheias. Apreendido pela leitura, o texto não tem de modo algum - ou ao menos totalmente - o sentido que lhe atribui seu autor, seu editor ou seus comentadores. Toda história da leitura supõe, em seu princípio, essa liberdade do autor que desloca e subverte aquilo que o livro the pretende impor. Mas esta liberdade leitora não é jamais absoluta. Ela é cercada por limitações derivadas das capacidades, convenções e hábitos que caracterizam, em suas diferenças, as práticas de leitura. Os gestos mudam segundo tempos e lugares, os objetos lidos e as razões de ler. Novas atitudes são inventadas, outras se extinguem. (CHARTIER, 2003, p. 236)

Com o incremento dessas tecnologias da informação, abre-se um leque de possibilidades para se refletir sobre as técnicas utilizadas pelos usuários da rede, ao criarem os seus espaços de interlocução, como declara Lévy (1999, p. 86): "os dispositivos informativos penetram e se entrecruzam no mais íntimo do sujeito". Temos assim, a transição das escritas do eu, com seus segredos e intimidades, que antes eram reservados às páginas de um diário confidencial, para o espaço virtual, percorrendo o mundo nas páginas da web; nessa passagem do antigo diário de um eu reservado e misterioso, às confissões públicas, no diário virtual, os sujeitos põem em xeque o secreto, propondo uma interlocução, sem eleger necessariamente um destinatário para as suas escritas; ao invés de desenvolver escritas no silêncio e na solidão do espaço privado, ${ }^{4}$ observam-se as escritas de fora, ${ }^{5}$ visando à captação dos olhares alheios, tornando, portanto, visiveis e públicas, as suas histórias da vida escolar. 0 sujeito, como é sinalizado por Bakthin (1999, p. 169): "que narra a sua vida insinua-se nela, de modo imediato, através dos outros, através dos narradores".

No que diz respeito à metodologia, a primeira etapa do trabalho foi a de constituir um corpus documental, no período de dezembro de 2009 a dezembro de 2010, acompanhando e gravando arquivos com os scraps ${ }^{6}$ dos usuários $^{7}$ das comunidades do Orkut de dez escolas ${ }^{8}$ no Rio de Janeiro, observando as escritas memorialísticas dos sujeitos relacionadas às suas histórias escolares. Em seguida, iniciaram-se os contatos com dez moderadores, ${ }^{9}$ para que eu pudesse ter acesso às comunidades, enviando-lhes uma carta $^{10}$ para a aproximação;

4 O diário pessoal escrito no quarto, em surdina, por exemplo.

5 Os diários pessoais que são tornados públicos, pela exposição na rede.

6 Trata-se de uma palavra da língua inglesa cujo significado pode ser recados, postagens que são encontradas nas redes sociais virtuais.

7 Optei em abreviar os sobrenomes dos sujeitos e esfumaçar as imagens gravadas nos arquivos, para preservar a identidade dos mesmos.

8 Públicas, particulares e confessionais: Colégio Pedro II/Engenho Novo/RJ, Colégio Santo Inácio/RJ, Colégio Sion/RJ, Centro Federal de Educação Tecnológica do Rio de Janeiro, Instituto Superior de Educação/RJ, Colégio Estadual Amaro Cavalcante/RJ, Colégio Militar/ RJ, Colégio Marista São José/RJ, Colégio de São Bento/ RJ, Instituto Abel/RJ.

9 Usuários responsáveis pelas comunidades escolares do Orkut.

10 Nessa carta, encaminhada em 14/09/2010, eu me apresento aos moderadores das comunidades escolares como pesquisador do ProPEd, enfatizando o meu interesse pelas postagens naquelas redes sociais do Orkut; terminei esse texto, deixando à disposição o meu endereço eletrônico, aguardando um possível contato daqueles sujeitos. 
obtive o retorno de quatro moderadores das seguintes comunidades escolares: Colégio Militar do Rio de Janeiro, Colégio Marista São José do Rio de Janeiro, Colégio de São Bento do Rio de Janeiro e Instituto Abel do Rio de Janeiro; a escolha das três escolas centenárias, situadas na cidade do Rio de Janeiro, foi um critério de seleção da pesquisa, uma vez que o Instituto Abel localiza-se em outra cidade do Estado do Rio de Janeiro. Assim, retomei o contato via e-mail, solicitando-lhes uma possivel resposta a algumas questões ${ }^{11}$ que foram inspiradas no questionário $^{12}$ formulado por Alberca (2000). Após receber as respostas dos questionários dos moderadores, procurei chegar aos usuários, ex-alunos das escolas, procurando entrecruzar dados com os posts dessas comunidades escolares do Orkut.

Sibilia (2008) explica que a utilização dos blogs, do Orkut e de outras redes sociais virtuais seriam estratégias que os sujeitos do tempo da internet colocam em ação para responder a essas novas demandas sociocultu-

11 Quando surgiu e qual(is) o(s) motivo(s) que o levou a ser um moderador na comunidade da sua escola no Orkut? Há algum estatuto para ser moderador? Qual o papel do moderador nesta comunidade virtual? Você usa algum mecanismo para verificar de fato que um novo usuário realmente teve algum vínculo com a sua escola? Qual o mecanismo? Quais as regras utilizadas para se permitir o acesso de um(a) novo(a) usuário(a)? Você armazena todas as escritas dos usuários? Caso afirmativo, quais os critérios que você utiliza para armazená-las? Com que frequência você acessa a sua comunidade? Por quê? Na sua opinião, qual(is) o(s) motivo(s) que estimula(m) o usuário a participar desta comunidade? Quais os Fóruns que você criou com mais postagens? Você poderia identificar qual é o tema mais recorrente nesta rede de sociabilidade virtual? Você já promoveu algum encontro presencial com os usuários da comunidade? Tem vontade de fazê-lo? Alguma vez você já leu algo postado por algum usuário, do qual você não tenha gostado? O que fez? Assinale quais os tipos de textos que você mais percebe circular na comunidade: poemas, canções, crônicas, recordações, relatos, pensamentos, artigos, correspondências, fotografias, imagens.

12 A pesquisa desse estudioso espanhol, aplicada em 1995 e 1996, na cidade de Málaga, aos alunos universitários e do ensino médio, num total de 702 sujeitos, entre homens e mulheres, procurava entender, se mesmo num mundo dominado pela cultura audiovisual, havia espaço para a cultura escrita de um diário. rais, balizando outras formas de ser e estar no mundo. Por sua vez, Lacerda (2003) sugere que o exercício de análise nas escritas autorreferenciais possibilitam revisitar os acontecimentos, as histórias escolares; entretanto, acredito que há de se observar também omissões e silenciamentos nesses posts. Será que essas narrativas representam apenas um registro escrito? Penso que também haja troca de ideias, fortalecimento de vínculos afetivos nessa rede social virtual.

\section{Escritas da extimidade:13 memórias da instituição escolar}

As reflexões de Eco (2010) nos inspiram a refletir que os suportes modernos são criados mais para a difusão do que para a conservação, endossando a questão da efemeridade das escritas do universo virtual. Será que os ex-alunos escritores estão conscientes disso? Essa reflexão é oportuna não só para a questão da memória que não será preservada, mas pode ajudar a entender também o tipo de escrita que é mais utilizado. Será que essa observação não é importante para se entender o laconismo e a linguagem telegráfica de muitos deles? Os posts dos ex-alunos nas comunidades escolares do Orkut pedem passagem para uma discussão da história de um tempo de redes sociais na internet. Os relatos a seguir também expõem as histórias de um tempo escolar:

Camargo 1042. no CMRJ de 70 a 81.Formado em Ed Fís. na UFRJ. Depois de um tempo girando pelo mundo, entrei concursado no Serviço Público Federal no Colégio Pedro II como prof Ed. Física. Vlw???HJ, por opção particular vivo em João Pessoa-PB, trabalho na CEFET-PB, Ex Escola Técnica Federal da Paraíba!!!! ${ }^{14}$

13 Termo cujo significado é o inverso de intimidade; Bauman (2012) nos ajuda a refletir que são as exibições contínuas das vidas dos sujeitos.

14 Escrita retirada do Fórum E depois do CM? - comunidade do Colégio Militar do Rio de Janeiro; postada pelo usuário Mauro R., em 17/10/2008. 
Que legau esse TOPIQUO!!!!Hj sou PM. Ahhh ja ia esquecendo, hj moro em Fortaleza-CE. ${ }^{15}$

MILICO!!!!Segui a carreira do EXÉRCITO. Abraços! ${ }^{16}$

Ao se ler os scraps no Fórum da comunidade do Colégio Militar do Rio de Janeiro -

E depois do CM? - observam-se as variações linguísticas Legau e Topiquo, que ressignificam as formas de narrar, expondo a extimidade dos ex-alunos. Nesse sentido, Castillo Gómez (2002) destaca a leitura fragmentada e descontínua presente no suporte digital. Um olhar mais atento às escritas memorialísticas destacadas permite observar pontos de interrogação, pontos de exclamação combinados às palavras grafadas com letras maiúsculas; brados linguísticos são os possiveis significados dessa combinação nas escritas desses usuários da comunidade do Colégio Militar do Rio de Janeiro. Será que esses ex-alunos param para perceber o quanto esses scraps são importantes para se pensar historicamente? Será que os usuários dessas redes sociais pensam na importância do que se produz por meio desses posts, haja vista a questão das fontes para a história das práticas escolares?

Os estudos de Menezes (2007), acenam que o cotidiano na escola deixa marcas do saber desejado: documentos, livros, material pedagógico, mapas, mobiliário escolar, elementos que não são matérias inertes, mas constitutivos de uma concepção de ensino determinada, de um tempo; quem sabe, se a tarefa do historiador da educação não seja juntar esses elementos da memória não apenas para a sua guarda, mas para a busca dos possiveis sentidos de sua utilização.

15 Escrita retirada do fórum E depois do CM? - da comunidade do Colégio Militar do Rio de Janeiro; postada pelo usuário Alcino R., em 27/07/2008.

16 Escrita retirada do fórum E depois do CM? - da comunidade do Colégio Militar do Rio de Janeiro; postada pelo usuário Thadeu S., em 12/08/2008.
Observa-se que além dos objetos, constituem também elementos dessa memória da instituição escolar músicas, fotos, filmes, vídeos, mapas da cidade e os próprios prédios escolares, que formam elementos físicos, visuais, auditivos, em movimento, e que registram, guardam e lembram fazeres da escola. Traços dessa memória da escola estão também nos próprios sujeitos: as falas dos alunos, dos professores, diretores, funcionários, articuladas com as falas dos que não foram para ela, mas a tiveram no seu desejo, precisam ser trazidas para a cena, encontrando canal para a sua expressão. Nessa acepção, os depoimentos nas comunidades escolares também oferecerem as memórias da instituição escolar, apresentando nas redes sociais virtuais uma nova materialidade para os registros de suas vivências de um tempo de escola.

Por seu turno, as reflexões de Mignot (2006) sugerem que, até bem pouco tempo, se valorizava apenas os relatos de homens públicos e a documentação oficial para fontes de pesquisas da história da Educação; no entanto, novas discussões, no âmbito das escritas de si, aguçaram historiadores da Educação a se voltarem para temas, objetos e fontes pouco examinados na historiografia da Educação. Quem sabe, se registrarmos ou arquivarmos essas escritas memorialísticas nessas redes sociais virtuais, possamos manter outras fontes para estudos e pesquisas sobre as histórias da Educação? Os depoimentos ${ }^{17}$ encontrados na comunidade do Colégio Marista São José do Rio de Janeiro, a seguir, valorizam essas fontes historiográficas.

17 Vale destacar que optei por abreviar, por opção metodológica, os sobrenomes dos sujeitos e esfumaçar as imagens gravadas nos arquivos para preservar a identidade desses usuários. 
Figura 1 - Fórum Quem foi aluno da Dona Wilma?

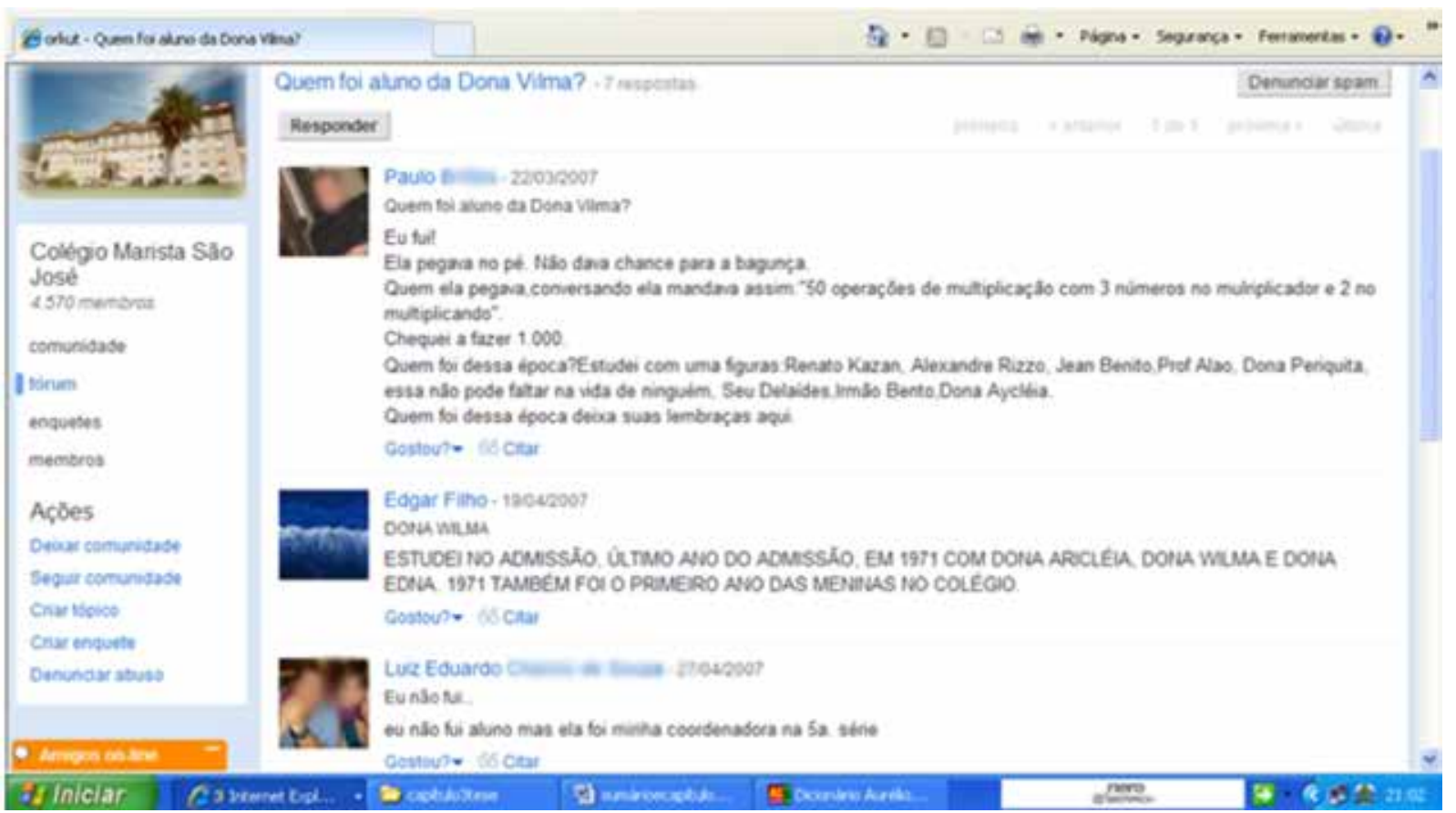

Fonte: Comunidade do Colégio Marista São José do Rio de Janeiro. Disponível em: <www. http://www.orkut. comunidade do Colégio Marista São José do Rio de Janeiro>. Acesso em: 12 set. 2011.

As escritas dos usuários no Fórum - Quem foi aluno da Dona Wilma? - podem se constituir em uma possibilidade de construção de memórias que evocam os cotidianos escolares, os conflitos vividos nas salas de aulas; é possivel observar que quando o assunto era disciplina, havia um rigor nas aulas da professora Wilma. Essas fontes podem ser vistas como documentos que possibilitam compreender e interpretar as tensões e contradições que perpassam o permanente processo de construção do cotidiano escolar.

Os testemunhos vivos dos usuários das comunidades escolares possibilitam inventariar, através de suas escritas e reflexões, aquilo que as suas memórias interpretam e compreendem, sugerindo novas reflexões para a vida daquelas escolas; são saberes produzidos na história inserida no contexto escolar, numa relação com o outro, em várias instâncias e localizações; assim, norteiam as suas relações com o mundo. Expressas em palavras, signos de comunicação, de transmissão, de preservação de um passado vivido e reconstruído no presente, as trajetórias de vida dos usuários, embora singulares e históricas, apresentam pontos de aproximação; as lembranças dos tempos da escola constituem uma dessas recorrências, representando momentos importantes no modo como esses usuários organizam e se posicionam nas relações sociais das quais participaram.

Imbuído de uma das discussões de Eco (2010, p. 19) sobre a efemeridade das mídias: "basta um pico de tensão ou outro acontecimento mais banal para desmagnetizar uma memória. Se houvesse um apagão longo não poderíamos usar nenhuma memória eletrônica", à medida que me aproximava dos depoimentos dos ex-alunos, vi a necessidade de gravar as suas escritas memorialísticas em arquivos para uma posterior consulta. Essa reflexão abre portas para se refletir sobre a questão do tempo de duração das narrativas dos suportes virtuais; nesse sentido, podemos observar a seguir os seguintes scraps postados na comunidade do Colégio de São Bento do Rio de Janeiro: 
Estudei na época do externato, da década de 70. Hoje, muito do que aprendi, devo a Dom Lourenço, Dom Estevão e a Dom Romualdo. Abração. ${ }^{18}$

Também sou da década de 70. Adorava Dom Justino e Dom Ambrósio. Abraço a todos. ${ }^{19}$

Os elogios, possivelmente às autoridades daquela instituição de ensino, ensejam o desejo dos usuários em registrar as suas homenagens na comunidade do Colégio São de Bento do Rio de Janeiro àqueles que contribuíram de alguma forma, na década de 1970, nas suas formações. Gravados em arquivos, esses scraps não poderão ser mais vistos on-line, por qualquer usuário, contudo, essa pesquisa pôde salvaguardar essas expressões de admiração aos religiosos daquela instituição de ensino.

Mas, se ao tentar mergulhar nas águas desse mar virtual, aproximando-se dessas escritas dos sujeitos nas redes sociais virtuais e não se conseguir salvaguardar esses testemunhos que vagueiam pelo mar da web? Ora, o suporte digital é também portador de histórias escolares, cujas narrativas exibem as suas experiências; portanto o ambiente virtual não pode ser mais ignorado, desconhecido pela historiografia:

Recusar o produto eletrônico é, hoje, uma impossibilidade. Não apenas porque cresce vertiginosamente seu mercado, mas porque a linguagem digital tem permitido a construção de outras práticas de leitura e escrita, que oferecem maneiras novas de organizar, hierarquizar e distribuir a informação e combinações de estímulos visuais e sonoros impensáveis para o suporte papel. (VIDAL, 2000, p. 36)

Os papéis, as cartas, os diários, os cadernos de receitas, os cartões pessoais, outras materialidades possivelmente guardadas nas

18 Escrita retirada do Fórum Alunos do Internato da comunidade do Colégio de São Bento do Rio de Janeiro; postada pelo usuário Alexandre S., em 14/08/2005.

19 Escrita retirada do Fórum Alunos do Internato da comunidade do Colégio de São Bento do Rio de Janeiro; postada pelo usuário Marcelo, em 10/08/2005. gavetas, nos armários, nas caixas, nos baús, são encontradas pelos pesquisadores da História da Educação para serem submetidas às operações historiográficas; o caminho aberto por esses estudos aguçou ainda mais o interesse por esses tipos de fontes, aproximando vários pesquisadores ${ }^{20}$ às escritas de si.

\section{Mas o que é guardar?}

Mignot (2006, p. 41) nos instiga a pensar: "guardar é diferente de esconder. Guardar consiste em proteger um bem da corrosão temporal para melhor compartilhar; é preservar e tornar vivo o que, pela passagem do tempo, deveria ser consumido, esquecido, destruído[...]"; nesse sentido, guardar denota o cuidado com certo material, para mantê-lo seguro, disponivel para consultas; quem sabe, aos olhares atentos dos pesquisadores, nessas fontes salvaguardadas, possam aparecer relatos e experiências de vida jamais revelados. Mas será que se guarda tudo? Quem sabe o eu lírico da composição, ${ }^{21}$ ajude-me a refletir sobre esta questão:

Eu hoje joguei tanta coisa fora

Eu vi o meu passado passar por mim

Cartas e fotografias gente que foi embora

A casa fica bem melhor assim [...]

Eu hoje joguei tanta coisa fora

E lendo teus bilhetes, eu lembro do que fiz Cartas e fotografias gente que foi embora A casa fica bem melhor assim $[. . .]^{22}$

20 Entre outros, no Brasil, destacam-se os trabalhos de Marina Maluf (1995), Maria José Motta Viana (1995), Ana Chrystina Venancio Mignot; Maria Helena Câmara Bastos; Maria Teresa Santos Cunha (2000), Zahidê Muzart (2010), Ângela de Castro Gomes (2004); na França, Philippe Lejeune (2008); na Espanha, Manuel Alberca (2000), António Viñao (2000), António Castillo Gómes; Verônica Sierra Blas (2005), na Argentina, Leonor Arfuch (2010).

21 VIANA, Herbert; TILLET, Tet. Tendo a Lua. Disponível em: <www.uol.com.br/letrasmusica>. Acesso em: 10 set. 2011.

22 Trecho da composição Tendo a Lua do grupo musical Os Paralamas do Sucesso. Disponivel em: <http://letras.terra.com.br/os-paralamas-do-sucesso>. Acesso em: 10 set. 2011. 
Nos seus versos poéticos, o eu lírico optou em jogar fora alguns materiais, afirmando que a sua casa ficaria melhor assim; assim, é possível perceber que a emoção motiva o sujeito a se desvencilhar de algum material, sobretudo quando for um manuscrito pessoal: uma carta, um bilhete, um diário. Ora, alguns materiais que guardam histórias individuais com marcas da escolarização, sobretudo nas redes sociais virtuais, também correm o risco de ser descartados, entretanto, por outros motivos.

Em seu texto, Vidal (2000) comenta que, nos últimos 250 anos, houve um crescente exponencial das publicações técnicas e científicas; e isso se duplica a cada 10 anos (LERNER, 1998). Ainda sobre este assunto, a autora revela duas informações: a primeira é que a biblioteca do congresso norte-americano acumula aproximadamente 80 milhões de itens e a cada dia, 7000 novas peças são acomodadas em suas estantes; a segunda, é que, no Brasil, a biblioteca nacional, oitava biblioteca do mundo, possui no seu acervo por volta de 8 milhões de itens (SANT'ANNA, 1997).

Por sua vez, as reflexões de Eco (2010) sugerem que há muito tempo se realizam congressos e se estudam meios diferentes para salvar todos os livros que abarrotam as bibliotecas; um dos meios possiveis para maior êxito, contudo, quase impossivel de realizar para todos os livros existentes, é escanear todas as páginas e copiá-las em um suporte eletrônico. Mas será que essa operação será suficiente? Como não bastasse uma resposta negativa, o próprio autor ressalta que os suportes para a transmissão e conservação de informações, da foto ao filme cinematográfico, do disco à memória pen drive, ${ }^{23}$ usados no computador, são mais pereciveis; ele cita a velha fita cassete para exemplificar o esforço feito, ao tentar desemaranhá-la, en-

23 Dispositivos de memória constituídos por memória flash. Disponivel em: <http://wwwgoogle.com>. Acesso em: 22 set. 2011. fiando um lápis no carretel, geralmente com resultado nulo.

É preciso refletir sobre a política de preservação, e sobre o descarte documental, uma vez que não há espaço suficiente para engavetar todos os impressos, publicações de todas as esferas, materiais para a leitura, tampouco corrermos o risco de legarmos ao futuro o que o passado nos legou: documentos que sobreviveram a uma espécie de seleção natural (intempérie, descuido humano ou outras razões). Quem sabe poder avaliar a documentação, descartando o desnecessário, criando condições de sobrevivência para esses documentos, sejam os caminhos possiveis para se pensar esse assunto?

Por outro lado, os altos custos também vaticinam profundas discussões, no âmbito da sobrevivência e do acúmulo de peças documentais: pessoal especializado, materiais específicos, tempo dispensado para os serviços, assim como investimentos para a recuperação de materiais protagonizam a história das alocuções e dos acúmulos dos materiais, é o que também se pode examinar nos estudos de Vidal (2000). Nessa acepção, talvez as novas tecnologias digitais também possam oferecer uma contribuição, um auxílio no quesito espaço e guarda de documentos. Então, qual será o estatuto que essa fonte assumirá?

Nem sempre a mudança radical do objeto, a mudança de sua forma física, por exemplo, pode implicar uma mudança radical do documento; ou, em outras palavras, transformá-lo em arquivos talvez possa descaracterizar sua importância como fonte. Nessa acepção, Karnal e Tatsch (2009) nos instigam a pensar que muda mais o olhar sobre a fonte do que a fonte em si. Assim, se o ditado popular francês "Le papier souffre tout" (KARNAL; TATSCH, 2009, p. 18 ), que pode ser traduzido por: "o papel aguenta qualquer coisa", for o mote, cujo significado está na força, no vigor do papel, que 
sofre calado, jamais se rebela contra as penas do autor, contra os dedos do escritor, quiçá, possa ser ressignificado por, as fontes transformadas em arquivos transcendem as forças dos papéis, não se rebelando contra os dedos do digitador ou muito menos contra a tinta da impressora.

Outro assunto que pode merecer destaque, na linha das discussões acerca da salvaguarda dos arquivos, é aquele relativo à obsolescência. Como dar visibilidade aos documentos? Os estudos de Vidal (2000) ainda destacam que os perigos da nova tecnologia, seus desafios, estão relacionados à redução da vida útil dos materiais utilizados pelos suportes digitais. Essa autora nos convida a pensar que um livro se abre sempre à leitura; o olhar atento do leitor para essa materialidade percorre as suas páginas, decifrando os segredos, processando os códigos partilhados e construídos historicamente, o que parece não acontecer com os dispositivos de arquivo como o disquete ou 0 CD-ROM; o fechamento de um livro não compromete em nada uma próxima investida do interlocutor; no entanto, para se ter acesso novamente aos conteúdos dos arquivos, a leitura deve ser mediatizada por uma máquina.

Por sua vez, Eco (2010) comenta que, com o desaparecimento dos diversos suportes, também desapareceram os computadores capazes de lê-los, e se alguém não copiou no suporte sucessivo tudo o que tinha no anterior, o perdeu irremediavelmente. Mas, como lidar com isso? As reflexões de Vidal (2000) fazem referência a Lerner (1998, p. 203), encaminhando possiveis trajetos: "a manutenção de um quadro de especialistas que [...] se ocupem em atualizar as informações [...] e a guarda, por parte das bibliotecas [...] de forma a permitir que cada peça seja lida no equipamento para a qual foi produzida". Quem sabe, assim possamos gravar essas fontes efêmeras, antes que algum sistema entre em pane:
Pane no sistema, alguém me desconfigurou Aonde estão meus olhos de robô?

Eu não sabia, eu não tinha percebido

Eu sempre achei que era vivo

Parafuso e fluído em lugar de articulação

Até achava que aqui batia um coração

Nada é orgânico, é tudo programado

E eu achando que tinha me libertado

Mas lá vem eles novamente

E eu sei o que vão fazer:

Reinstalar o sistema[...]

Pense, fale, compre, beba

Leia, vote, não se esqueça

Use, seja, ouça, diga...

Não senhor, Sim senhor[...] ${ }^{24}$

As escritas transitivas do espaço da web estão à disposição dos navegadores, tripulantes de uma produção histórica do tempo presente, para serem decifradas, analisadas, problematizadas, do mesmo modo que outras fontes historiográficas ${ }^{25}$ apresentam vivas as vozes que clamam por visibilidade nos territórios da História da Educação, como pode se ver nas escritas a seguir:

Eu fui aluno da sua mãe em 1970, na 5á série. Adorava muito a professora Aryclea. Bons tempos! Viajamos ao sul do Brasil com a sua mãe!26

Sou sua filha, e tb estudei nos 2 Maristas na área biomédica. Gostaria de obter histórias e fotos no orkut. Vocês podem me postar? ${ }^{27}$

Eu fui aluna da sua mãe, inclusive viajei em uma excursão $p /$ o sul e ela ficou no meu quarto. Eu gostava bastante da sua mãe e ela foi uma ótima profa. Foram ótimos tempos... Mande lembranças $p /$ sua mãe. Eu acho que tenho uma

24 PITTY, Leone. Admirável chip novo. Disponível em: $<$ http://letras.terra.com.br/pitty>. Acesso em: 12 set. 2011.

25 Papéis, cadernos, diários, cartas etc.

26 Escrita retirada do Fórum - Quem foi aluno da professora Aryclea Marinho? - da comunidade do Colégio Marista São José do Rio de Janeiro; postada pelo usuário Luiz E., em 29/08/2005.

27 Escrita retirada do Fórum - Quem foi aluno da professora Aryclea Marinho? - da comunidade do Colégio Marista São José do Rio de Janeiro; postada pela usuária Márcia M., em 08/11/2005. 
foto com ela em Foz do Iguaçu, vou procurar e te falo depois. ${ }^{28}$

O Fórum - Quem foi aluno da professora Aryclea Marinho? - da comunidade do Colégio Marista São José do Rio de Janeiro, traz, nas escritas memorialísticas dos usuários, a saudade da professora. Nesses scraps, também as histórias de uma excursão ao sul do Brasil, mais especificamente, a Foz de Iguaçu, são revisitadas, deixando muitas saudades. Esses sujeitos que postam as suas memórias efêmeras são os protagonistas de uma história de um tempo escolar da qual eles fizeram parte; nessa discussão sobre repensar o tempo presente:

O historiador trabalha sobre o passado, mesmo próximo, isto é, sobre o que está abolido. Não que ele conceba sua prática unicamente como uma espécie de retorno das cinzas do passado a um presente que seria totalmente desconectado daquele. Bem ao contrário, esse historiador, qualquer que seja sua especialidade cronológica, bebe em seu presente e, longe de pensar que é de nenhum tempo e de país nenhum, ele sabe que está ligado por múltiplas fibras a seu tempo e à comunidade à qual pertence. [...]. (SIRINELLI, 1999, p. 78)

Em seu artigo, Meneses (2009) destaca que nos tornamos participantes dessas histórias, na medida em que a simultaneidade da informação nos leva à condição de testemunhas; nesse cenário, um elemento se situa como ponto fundamental: os usos em torno da constituição da memória e da história; essa constatação acabou sendo capital para a mudança de perspectivas que as pessoas comuns tinham e passaram a ter em sua relação ao tempo e nas suas maneiras de pensar historicamente o seu cotidiano.

Por outro lado, é também a partir dos seus vários discursos narrativos que as temporalidades são significadas e articuladas; exemplo disso, é a submissão do presente e, consequentemente, o passado a uma contínua exposição (SIBILIA, 2008). Examinamos essa reflexão na próxima figura.

Figura 2 - Fórum Quem estudou na década de 1970

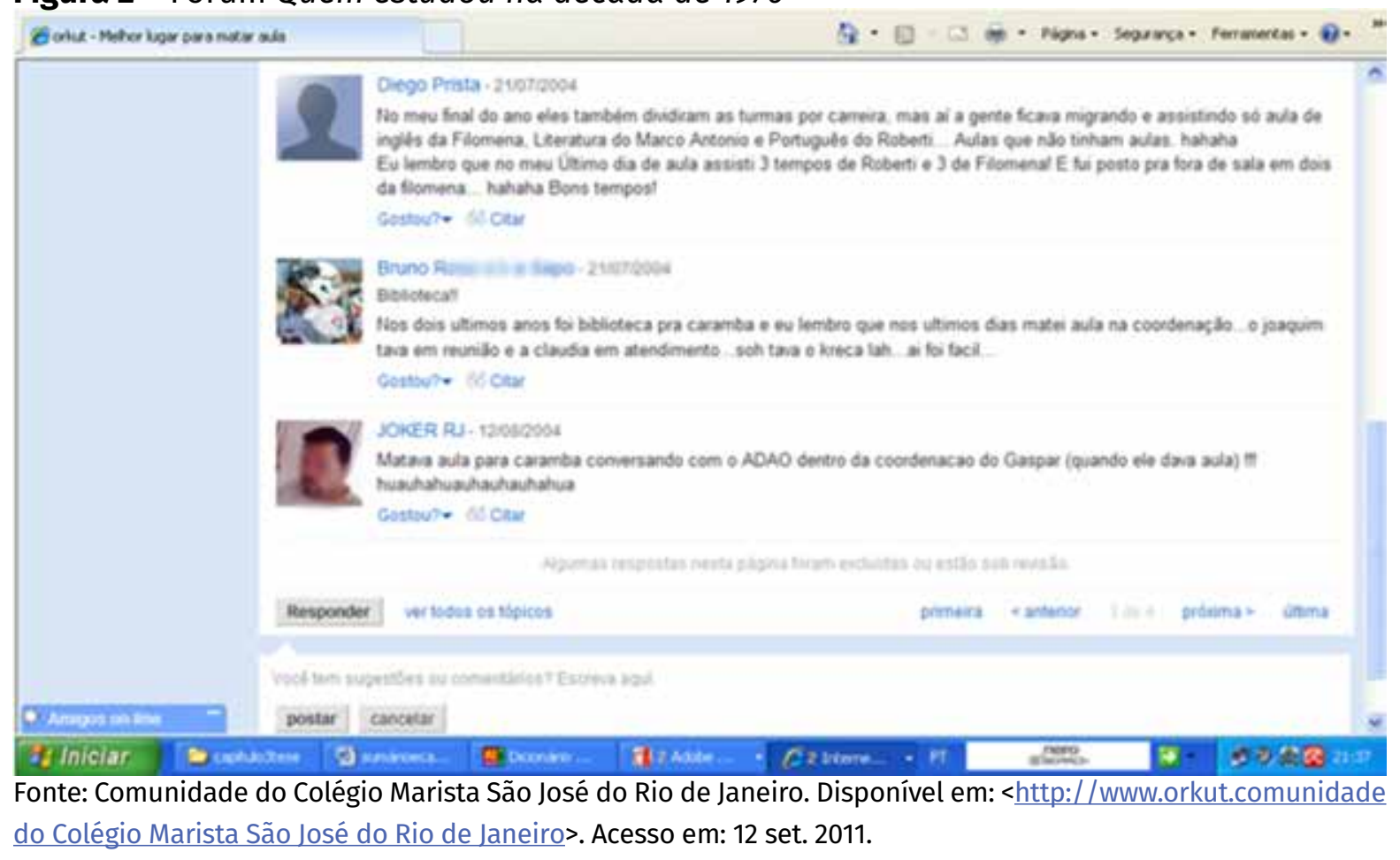

28 Escrita retirada do Fórum - Quem foi aluno da professora Aryclea Marinho? - da comunidade do Colégio Marista São José do Rio de Janeiro; postada pela usuária Ana P., em 13/11/2005. 
Os posts dos usuários Diego P., Bruno R. e Joker RJ deixam entrever que, quando o assunto era matar aulas, naquela instituição de ensino, talvez não tivesse sido uma tarefa tão difícil para os estudantes a ausência de suas respectivas salas de aulas; nas suas escritas memorialísticas, a coordenação do professor Gaspar, assim como a biblioteca eram os espaços mais frequentados por aqueles sujeitos nessa situação rotineira.

Há de se pensar também nos estatutos contraditórios e ambíguos dessas memórias efêmeras, que podem ocasionar possíveis descartes nessas redes sociais; se, por um lado, é possivel observar a necessidade de nunca esquecer o fato, torná-lo inesquecível, valorizando, assim, as experiências, de outro, há a necessidade de ocultar, silenciar, ou pela necessidade de se preservar algo depois de um acontecimento.

Se um possivel sentido é atribuído à narrativa revelada pelo ex-aluno Joker RJ, em relatar que matava aula à beça, conversando com Adão, dentro da coordenação do Gaspar, por outro lado, há de se perceber outro sentido, o de comprometer a figura do coordenador Gaspar, nessa investida do ex-aluno Joker RJ. Afinal, o usuário estava ausente de uma sala de aula.

\section{Referências}

ALBERCA, Manuel. La escritura invisible: testimonios sobre el diário intimo. Madrid: Sendoa, 2000.

ARFUCH, Leonor. 0 espaço biográfico: dilemas da subjetividade contemporânea. Rio de Janeiro: EDUERJ, 2010.

BAKHTIN, Mikhail Mikhailovitch. Marxismo e filosofia da linguagem. Tradução de Michel Lahud e Yara Frateschi Vieira. São Paulo: Hucitec, 1999.

BAUMAN, Zygmun. Isto não é um diário. Tradução de Carlos Alberto Medeiros. Rio de Janeiro: Zahar, 2012.

\section{Considerações finais}

Ancorando-me nos estudos de Lejeune (2008) e Alberca (2000), pesquisadores das escritas intimas, é possivel refletir que esses depoimentos condenados a pouca duração, criam chances para analisar os usos e as funções da cultura escrita, como a arte e a literatura também contribuem para entender melhor cada sociedade (CASTILLO GÓMES, 2002).

Se essas redes virtuais também são feitas de produções e tensões que nos permitem elaborar e partilhar sentidos, talvez ali mesmo, na fluidez e na intensidade dos fluxos, nos borramentos das fronteiras virtuais, seja possivel observar textos, histórias; mesmo construídas em trânsito e em processo, quem sabe, essas escritas possam se fortalecer. Resta o desafio de não deixarmos desmoroná-las, como os castelos de areia são abatidos pelos ventos do deserto, mas deixar que se fortaleçam, mesmo no universo efêmero, no imperativo da conexão, sob os olhares dos usuários do universo digital.

Mas quem disse que isso é o fim? Se a efemeridade habita os suportes virtuais, certamente, amanhã, outras redes sociais virtuais estarão franqueadas também à visita dos pesquisadores da História da Educação.

BLOCH, Marc. Apologia da história ou o ofício do historiador. Rio de Janeiro: Ed. Jorge Zahar, 2001.

BRITTO, Sérgio. Epitáfio. Disponivel em: <http:www. musica.uol.com.br>. Acesso em: 14 out. 2010.

CASTILLO GÓMEZ, Antônio. (Org.). História de la cultura escrita. Madrid: Trea, 2002.

; BLAS, Verônica Sierra. (Orgs.). Letras bajo sospecha: escritura y lectura em centros de internamiento. Madrid: Trea, 2005.

CHARTIER, Roger. Formas e sentido. Cultura escrita: 
entre distinção e apropriação. Tradução. de Maria de Lourdes Meirelles Matencio. São Paulo: Mercado de Letras, 2003.

$E C O$, Umberto. Eletrônicos duram dez anos. Jornal Estado de São Paulo, 13/03/2010. Disponivel em: $<$ http://www.estadao.com.br/>. Acesso em: 10 mar. 2010.

GOMES, Ângela de Castro. (Org). Escrita de si, escrita da história. Rio de Janeiro: FGV, 2004, pp. 7-26.

KARNAL, Leandro; TATSCH, Flavia Galli. Documento e história: a memória evanescente. In: PINSKY, Carla Bassanezi; LUCA, Tânia Regina. (Orgs.). 0 historiador e suas fontes. São Paulo: Contexto, 2009. p. 9-26.

LACERDA, Lilian de. Álbum de leitura: memórias de vida, histórias de leitoras. São Paulo: Unesp, 2003.

LEJEUNE, Philippe. 0 pacto autobiográfico: de Rousseau à internet. Tradução de Jovita Maria Gerheim Noronha e Maria Inês Coimbra Guedes. Belo Horizonte: UFMG, 2008.

LERNER, Fred. The story of libraries. New York: Continuum, 1998.

LÉVY, Pierre. Cibercultura. Tradução de Carlos Irineu da Costa, São Paulo: Ed. 34, 1999.

LISPECTOR, Clarice. Perto do coração selvagem. Rio de Janeiro: Nova Fronteira, 1980.

MALUF, Marina. Ruídos da memória. São Paulo: Siciliano, 1995.

MENESES, Sônia. Passageiros entre palavras fugazes: pensar o tempo presente entre mídia, história e memória. Revista eletrônica História Agora, v. 7, p. 1-16, 2009. Disponivel em: <http:// www.historiagora.com>. Acesso em: 16 set. 2011.

MENEZES, Jaci Maria Ferraz de. Memória. Autobiografia e relatos de formação: a escola, a sala de aula e o fazer docente. In: SOUZA, E. C. de. História de vida e formação de professores, boletim 1, março de 2007. p. 23-40. Disponivel em: <http://tvbrasil.org.br/fotos/salto/series/165212>. Acesso em: 12 set. 2011.

MIGNOT, Ana Chrystina Venâncio. Da gaveta à vitrine: exposições sobre a escrita. In SOUZA, E. C. de.
(Org.). Autobiografias, histórias de vida e formação: pesquisa e ensino. Porto Alegre: Edipucrs, 2006. p. 207-224.

MIGNOT, Ana Chrystina Venâncio; BASTOS, Maria Helena Câmara; CUNHA, Maria Teresa Santos. (Orgs). Refúgios do eu: educação, história e escrita autobiográfica. Florianópolis: Ed. Mulheres, 2000.

MUZART, Zahidé Lupinacci. Do navegar e de navegantes. In: CONGRESSO NACIONAL DA ABRALIC, 6., 1998, Florianópolis. Anais... Florianópolis: UFSC, 1998. Disponivel em: <http:// www.tripod.com/zahide.htm>. Acesso em: 20 jul. 2010.

PITTY, Leone. Admirável chip novo. Disponivel em: $<$ http://letras.terra.com.br/pitty>. Acesso em: 12 set. 2011.

REGO, Teresa Cristina. Memórias de escola: cultura escolar e constituição de singularidades. Petrópolis, RJ: Vozes, 2003.

SANT'ANNA, Affonso Romano. Libraries, social inequality and the challenge of the twenty-first century. In: GRAUBARD, Stephen; LECLERC, Paul. Books, brics \& bites: libraries in the twenty-first century. New Brunswick (USA), London (UK): Transaction Publisher, 1997. p. 126-144.

SIBILIA, Paula. 0 show do eu: a intimidade como espetáculo. Rio de Janeiro: Nova Fronteira, 2008.

SIMÕES, Robson Fonseca. Escritas à deriva: testemunhos efêmeros nas comunidades do Orkut. 2012. 242 f. Tese (Doutorado em Educação) - Programa de Pós-Graduação em Educação - ProPED, Universidade do Estado do Rio de Janeiro, Rio de Janeiro, 2012.

SIRINELLI, François. Ideologia, tempo e história. In: CHAUVEAU, Agnes. Questões para a história do presente. São Paulo: Edusc, 1999. p. 73-92.

TFOUNI, Leda Verdiani. Letramento e alfabetização. São Paulo: Cortez, 1995.

THOMSON, Alistair. Recompondo a memória: questões sobre a relação entre história oral e as memórias. Revista Projeto História - Ética e História Oral, Programa de Estudos Pós-Graduados em História, São Paulo, Ed PUCSP, v. 15, p. 51-84, 1997. 
VIANA, Maria José Mota. Do sótão à vitrine: memória de mulheres. Belo Horizonte: EDUFMG, 1995.

VIANA, Herbert; TILLET, Tendo a Lua. Disponível em: <www.uol.com.br/letrasmusica>. Acesso em: 10 set. 2011.

VIDAL, Diana Gonçalves. Fim do mundo do fim: avaliação, preservação e descarte documental. In: FARIA FILHO, Luciano Mendes de. (Org.). Arquivos, fontes e novas tecnologias: questões para a histó- ria da educação. Campinas, SP: Autores Associados, 2000. p. 31-44.

VIÑAO, Antonio. Las autobiografias, memórias y diários como fuente histórico-educativa: tipologia e usos. TEIAS, Revista da Faculdade de Educação, UERJ, n. 1, p. 82-97, jun. 2000.

Recebido em: 11.09.2016

Aprovado em: 10.11.2016

Robson Fonseca Simões é doutor em Educação, professor do Departamento de Ciências da Educação, Núcleo de Ciências Humanas, da Universidade Federal de Rondônia - UNIR, Campus Porto Velho. Telefone institucional: 69 2182-2142. Docente do Programa de Pós-Graduação em Educação (PPGEE/MEPE/UNIR). e-mail: fonsim2000@hotmail.com.

Núcleo de Ciências Humanas, Departamento de Ciências da Educação, UNIR, Campus Porto Velho, BR n. 364, km 9,5, Porto Velho, RO, CEP: 76.801-059. 